\title{
Relative Levels of Tolerance to Pea Aphid (Acyrthosiphon pisum Harris) in Selected Lentil Genotypes in Ethiopia
}

\author{
Geteneh Mitku \\ Ethiopian Institute of Agricultural Research, Fogera national rice research and training center \\ Address; P.O.BOX 1937, Bahirdar, Ethiopia
}

\begin{abstract}
The experiment was conducted with five lentil genotypes of known reaction to pea aphid for resistance. The trail was carried out with two identical but separate experiments as infested and un-infested trial under DZARC lath house. Infested seedlings were compared with uninfested ones in terms of plant height, biomass, root weight, and leaf area to quantify tolerance. The field performance of those lentil genotypes used in the experiments was assessed at Chefe Donsa substation, which is found in the East Shewa administrative zone, Ethiopia. Alemaya(lentil varity) reduces pea aphid damage cumulatively by the reduced percent dry and fresh biomass, percent plant height reduction and increased dry biomass, plant re-growth after 12 days of infestation compared with other tested genotypes, thus Alemaya had high tolerance to A. pisum. Similarly, comparable tolerance was found on ILL-7664 which exhibited longer plant re-growth, increased dry biomass after 12 days of infestation compared with other tested genotypes, except Alemaya. Chalow also showed reduced percent plant height and dry biomass reduction and increased leaf number after 12 days of infestation. Using genotypes that had tolerance for pea aphid management is wise decision as it reduces selection pressure on A. pisum. Alemaya (genotype which had tolerant resistance) is more important for integrated pest management program (IPM) than all the remaining tested genotypes.
\end{abstract}

Keywords: tolerance, field resistance, pea aphid, lentil

DOI: $10.7176 / \mathrm{JBAH} / 11-22-02$

Publication date: November $30^{\text {th }} 2021$

\section{Introduction}

Nevertheless, wide use of synthetic insecticides for the control of major pests has also resulted in more pest problem due to upset of balance between insect and natural enemies, insecticide resistance development, and effect on non target beneficial organisms (Thomas and Waage, 1996). Such adverse effects of dependence on chemical insecticides prompted for an increased interest in the development of integrated pest management (IPM) program, which is sustainable and environmentally friendly pest management method. IPM uses different pest management tactics such as cultural practices, host plant resistance, semi chemicals, biological control, etc. in a compatible manner with due consideration of the ecology (Dent, 2000).

Host plant resistance, HPR has been widely studied and established as a viable strategy for insect pest control (Zhu et al., 2005). Brewer et al. (1998) argued that in the absence of natural enemies and chemicals present and future populations of aphids depend largely on host plants because resistant cultivars sustain lower numbers of aphids with mostly green leaves, whereas susceptible plants sustain large numbers of aphids showing leaf curling and chlorosis. Combination of host plant resistance and chemical control can help reduce not only the cost of chemical control, but also the residue problems associated with chemicals (Smith, 2005). Thus, resistant varieties do not guarantee absolute and long-term control, especially for aphids that could develop biotypes in situations where resistance is controlled by a single major gene (Reese et al., 1994). So, developing multiple gene resistance plant may be good option to tackle these problems. Plants respond to herbivore attack through an intricate and dynamic defense system that includes structural barriers, toxic chemicals, and attraction of natural enemies of the target pests (Karban, 2011). Large number of lentil germplasm were evaluated for resistance to pea aphid in DZARC at different years. From 16 promising genotypes that gave better yield under the prevailing aphid infestation pressure Alemaya, ILL-7664, ILL-4422, ILL-2595 and R-186 were included in current study.

Tolerance is the ability of a plant to withstand or recover from insect herbivory without inflicting any adverse effect on the insect (Smith and Clement, 2012). Among the three components of resistance, tolerance is considered most useful because the risk of biotype development is reduced on such plants (Robinson et al. 1990). Plant tolerance measure response of a plant to a given level of damage caused by insect herbivore, and it doesn't reflect amount of damage caused by the insect (Farrell, 1977). The objective of experiment was to Asses field and laboratory resistance of lentil to pea aphid

\section{Material and Method}

Description of the Study Area

The resistance mechanism experiments were conducted in a lath house $\left(22.5\right.$ to $23.6{ }^{\circ} \mathrm{C}$ mean temperature and 
$60 \%$ to $70 \%$ relative humidity) at Debre Zeit Agricultural Research Center (DZARC). A field study was also conducted to get preliminary information on the association of resistance traits under lath house and field conditions at Chefe Donsa.

\section{Plant Material}

Lentil genotypes namely Alemaya, Chalew, R-186, ILL-2595, ILL-4422, and ILL-7664, which were identified as resistant to pea aphid in a preliminary study and one susceptible genotype i.e. ACC-21688 were included in lath house and field experiments. The evaluations of lentil genotypes under field conditions were conducted between 1999 and 2011 during which some pea aphid resistant genotypes were identified (DZARC, 2012). Alemaya, R-186 and Chalew are released varieties. Chalew, (the name chalew was given because of its tolerance to pea aphid under field condition) was selected based on its tolerance (Kemal and Tibebu, 1994). Seeds of each genotype were obtained from DZARC. Black soil, the common soil type in the area, on which lentil crops are traditionally grown, was used for pot experiment.

\section{Insect Culture}

Pots (20 cm diameter) were filled with black soil and seeds of EL-142 (susceptible variety) were planted at rate of $2 \mathrm{~g}$ per pot for aphid colony establishment. Pots were watered as required. Pea aphids were collected in August 2017, from lentil field near to Debre Zeit Agricultural Research Center and potted seedlings were infested with single aptera adult pea aphid, which was allowed for 24 hcurrents to deposit nymphs. After 24 hcurrents, all the nymphs and the adult mother were removed from the pot, leaving only one new born nymph. The colony established from this single nymph was raised on El-142 in the lath house by replacing old infested pots with new pots at seven and ten-day interval. The colonies were maintained under natural light and photoperiod condition at an average temperature of 22.5 to $23.6^{\circ} \mathrm{C}, 12: 12 \mathrm{~L}: \mathrm{D}$ and relative humidity of $60 \%$ to $75 \%$. Adult apterous $\mathrm{A}$. pisum found in this colony were used for all lath house (antibiosis, tolerance and antixenoss) experiments.

\section{Tolerance test}

To quantify tolerance, the procedure of Unger and Quisenberry (1997) was followed, which is done by conducting two identical but separate experiments as infested and un-infested trial under DZARC lath house. Two seeds of each genotype were grown per pot $(20-\mathrm{cm}$ diameter and $30 \mathrm{~cm}$ height $)$ and thinned to one vigorous plant for infestation. Plant based economic threshold level of pea aphid on lentil is when aphid reached $\geq 7$ aphids/plant (Homan et al,1991). That is why experimental groups were infested with 10 adult $\mathrm{A}$. pisum per plant when seedlings reached at V5 (the first multifoliate leaf has unfolded at the fifth node) whereas control groups were left un-infested. Each pot was covered with cylindrical transparent plastic cage of $15 \mathrm{~cm}$ diameter by $80 \mathrm{~cm}$ height as described in antibiosis test. Infested and un-infested pots were placed side by side to expose them to the same environmental conditions. The trial was conducted under a completely randomized block design with five replications. Infested plants were examined every 24 hcurrents and new born excess aphids were removed to maintain a constant number of 10 adult aphids per plants. Tolerance can be quantified by comparing the height of re-growth and dry weight of plants (Baker et al., 1981). Hence height of re-growth, dry weight and other related parameters were used to quantify tolerance as a mechanism of resistance.

\section{Field performance of selected lentil genotypes against pea aphid}

The field performance of those lentil genotypes used in the aforementioned experiments was assessed at Chefe Donsa substation of DZARC, which is found in the East Shewa administrative zone, Oromia region. The substation is located at $8^{\circ} 97^{\prime} \mathrm{N}$ and $39^{\circ} 12^{\prime} \mathrm{E}$ with an elevation of 2392 meters above sea level. Genotypes were tested in RCBD with 10 replications. The first five replications were sprayed with Dimethoate $50 \%$ E.C. at the rate of $2 \mathrm{~L} / \mathrm{ha}$ in spray volume of $200 \mathrm{~L} / \mathrm{ha}$ water per hectare using hand operated knapsack sprayer, when the insect infestation on lentils reached at economic threshold level (on average 20 pea aphid per $130 \mathrm{~m}^{2}$ counting board). Each genotype was sown at the rate of $60 \mathrm{~kg} /$ ha on plot of $4 \mathrm{~m} \times 2 \mathrm{~m}$. The spacing between rows, plots within replication and protected and unprotected group was $0.25 \mathrm{~m}, 0.5 \mathrm{~m}$ and $1 \mathrm{~m}$, respectively. The lentil growth stage at the time of spray was first bloom stage (R-1) and then pea aphid counting was continued for fcurrent times at 10 days interval.

\section{Data collection}

All tolerance test data were collected on two identical experiment, infested with pea aphid and un-infested plants after 12 days of infestation. The height of each plant, whether infested or not, was measured before infestation at the onset of the tolerance test and at the end of the test period, which was 12 days.

Number of leaves per plant was counted, fresh biomass per plant also weighed with sensitive balance at the end of the test period. Each harvested plant was put separately in labeled paper bag and dried in an oven at $50^{\circ} \mathrm{C}$ 
for $72 \mathrm{~h}$ and weighed by sensitive balance.

Total leaf area per a single plant was measured two weeks after infestation on both infested and un infested plants destructively using a portable leaf area meter (model CI-202, USA). All green leaves were separated (excluding leaf sheaths) from the plant then the leaf area was measured by leaf area meter. To provide a relative degree of height and weight reduction, plant height and weights of each entry per replication were standardized using the formula Percent reduction $=(1-($ infested/un-infested $) * 100)$, (Unger and Quisenberry, 1997).

Field performance data

Aphids number were counted on $130 \mathrm{~cm}^{2}$ counting board on fcurrent spots per plots at 10 days interval. The counting board was $39 \mathrm{~cm}$ long and $20 \mathrm{~cm}$ wide, which was subdivided in to six $10 \mathrm{~cm} \times 13 \mathrm{~cm}$ rectangles. At each sampling spots, pea aphid and other insects dislodged on the counting board were counted from two randomly chosen rectangles. The coccinellids and other predator were recorded but their average density was less than one per $130 \mathrm{~cm}^{2}$, so discarded from analysis. Pods with and without grain was counted on both protected and unprotected plot per 10 plants then converted to their average number and finally converted to percentage of pods per plant with grain. The grain yield per plot for both protected and unprotected lentil genotypes was measured after threshing, cleaning and drying the grain using sensitive balance in the seed quality laboratory, DZARC. The mean grain yield from protected and unprotected plot were used to calculate yield losses and compare genotypes.

Damage assessment or the percentage yield loss due to pea aphid was calculated for each treatment using the formula suggested by Walker (1987) and as the difference between insecticides treated and untreated plots. Yield loss $(\%)=((\mathrm{Y} 1-\mathrm{Y} 2) / \mathrm{Y} 1 \times 100)$, where, $\mathrm{Y} 1$ is the mean yield of protected plots, $\mathrm{Y} 2$ is the mean yield of unprotected plots

\section{Data Analysis}

Data collected for tolerance test and field performance were tested for normality and homogeneity of variance before statistical analysis, when the data fulfilled the assumptions of ANOVA, then the data were subjected to Analysis of Variance using general linear model (PROC GLM, SAS Institute, 2002). Whenever, the ANOVA show significant difference, means were separated using Tukey's Honestly Significant Difference test at $(\mathrm{P}<0.05)$.

\section{Result and discussion \\ Tolerance Test \\ Plant height percent reduction}

Plant height reduction $(\%)$ was significantly $(\mathrm{p}<0.05)$ different among tested genotypes (Table 1$)$. All resistant genotype had significantly less percent of plant height reduction than the height reduction in susceptible control. Smallest plant height reduction caused by 10 pea aphids feeding for 12 days was on Alemaya, followed by ILL7664 and Chalew; whereas the highest plant height reduction was recorded on ACC-21688 (Table 1). The small plant height reduction is an indicator of tolerance, plants which withstand 10 pea aphids for 12 days feeding. Thus, Alemaya, ILL-7664 and Chalew which had smallest percent of plant height reduction are tolerant to pea aphid based on this parameter. After 12 days of infestation, all infested groups had shorter plant height than uninfested genotypes implying that aphid infestation reduces plant height. Report of Alemtaye and Westhuizen (2004) on lentil genotype showed plant height reduction of 31.1-55.5 \% (ILL-8127- Spanish Brown). Plant height percent reduction of current study on resistance genotype (Alemaya) is smaller than previous report, this may due to presence of high tolerance ability on genotype, Alemaya to pea aphid than previous tested genotype.

\section{Plant biomass}

\section{Dry biomass percent reduction}

Dry biomass percent reduction due to pea aphid feeding for 12 days showed that highly significant $(\mathrm{p}<0.01)$ among tested genotypes (Table 1), even though percent reduction on ILL-4422 and ILL-2595 showed nonsignificant $(p<0.05)$. Percent reduction difference among genotypes may due to level and types of resistance difference. Significantly the smallest dry biomass reduction caused by pea aphid feeding showed on Alemaya followed by Chalew and ILL-7664, whereas the highest was on the ACC-21688. Tolerant plants support large insect population with little damage or yield loss and have value in maintaining predator and parasite population (Horber, 1972). Hence the least \% of dry biomass reduction on Alemaya and intermediate reduction on Chalew and ILL-7664 indicated that, they have comparable levels of tolerance when compared to remaining resistant tested genotype based on this parameter. Study on aphids in north America, high levels of aphid infestation in were associated with a $20-25 \%$ biomass reduction (Myers et al. 2005). Plant dry biomass \% reduction in the current study due to 10 aphid /plant for 12 days infestation range from 20.14 to $49.95 \%$ loss on Alemaya and ACC-21688 respectively, more reduction in current current study compared to previous one implies that previous study genotypes may have more resistance ability than current tested genotypes. This is the first report 
to give insight information about range of reduction of biomass on tested genotype and also first report to categories Alemaya, as tolerant genotypes.

\section{Fresh biomass percent reduction}

Fresh biomass percent reduction due to pea aphid feeding for 12 days at vegetative stage showed significantly $(\mathrm{p}<0.05)$ variable among tested genotypes (Table 1), except R-186, ILL-4422, Chalew and ILL-7664. The largest fresh plant biomass percent reduction was on ACC-21688, whereas the smallest reduction was on ILL-2595 and Alemaya without significant difference. The fresh biomass percent reduction difference among tested genotypes may due to resistance level and type difference. Alemaya and ILL- 2595 which had smallest fresh biomass percent reduction had tolerant resistance mechanism based up on fresh biomass percent reduction. Fresh biomass percent reduction may not exactly quantify tolerance because plants may have different potential to maintain moisture content, this moisture content may have confounding effect, so observing and considering dry biomass and plant height is wise decision to quantify tolerance. Correlations between plant height reduction, fresh biomass reduction and dry biomass reduction showed strong positive relationship. The biomass loss amount due to pea aphid infestation at various crop growth stages were calculated per ha within the range of $50.0-88.9 \%$ for lentil varieties (Adane et al, 2012). Fresh plant biomass, \% reduction in the current study range from $24.13 \%$ to $43.0 \%$ in Alemaya and ACC-21688, which is less than previous study. The reason for smaller reduction in the current study may due to more tolerance ability of genotypes included in current experiment than previous one.

\section{Leaf area and leaf number percent reduction}

Leaf area percent reduction of genotypes showed significantly $(p<0.05)$ different among tested genotypes (Table 1). Similarly leaf number of genotypes percent reduction after 12 days infestation showed statistically significant difference. All resistant genotype had significantly less leaf area and leaf number reduction than in susceptible control. Smallest leaf area reduction caused by pea aphid feeding was on Alemaya and ILL-7664; whereas the highest leaf area reduction was recorded on ACC-21688 (Table 1), genotypes with smallest leaf area and leaf number percent reduction is indicator of presence of tolerance resistance, which withstand 10 pea aphids for 12 days feeding. Leaf area reductions due to pea aphid infestation ranged from 14.16 to $34.07 \%$ for Alemaya and ACC-21688 and leaf number reduction ranged from 16.03 to $28.57 \%$. Leaf area reductions in current current study was lower when compared with (Mahmut et al 2007) who found that leaf area damage of 31-71\% by Greenbug. The difference between current and previous report based on leaf area percent reduction may due to insect and crop difference, different insects may have different ability on leaf area reduction. From this results Alemaya can tolerate the pest damage and give lower leaf number and leaf area reduction.

Table 1. Fresh and dry plant biomass of lentil genotype after infestation with A. pisum

\begin{tabular}{|c|c|c|c|c|c|}
\hline & Plant height & Fresh biomass & Dry biomass & Leaf area & Leaf number \\
\hline Genotype & $\begin{array}{l}\text { Percent } \\
\text { reduction }\end{array}$ & $\begin{array}{l}\text { Percent } \\
\text { reduction }\end{array}$ & $\begin{array}{l}\text { Percent } \\
\text { reduction }\end{array}$ & $\begin{array}{l}\text { Percent } \\
\text { reduction }\end{array}$ & $\begin{array}{l}\text { Percent } \\
\text { reduction }\end{array}$ \\
\hline Alemaya & $15.63 \mathrm{a}$ & $24.13 a$ & $20.14 \mathrm{a}$ & $14.16 \mathrm{a}$ & $16.75 a$ \\
\hline Chalew & $20.61 b$ & $31.06 \mathrm{ab}$ & $29.44 \mathrm{ab}$ & $17.12 \mathrm{ab}$ & $19.03 \mathrm{a}$ \\
\hline R-186 & $28.42 \mathrm{c}$ & $35.63 \mathrm{ab}$ & $45.00 \mathrm{bc}$ & $21.61 b$ & $21.81 \mathrm{ab}$ \\
\hline ILL-2595 & $26.85 b c$ & $23.50 \mathrm{a}$ & 34.99abc & $17.35 \mathrm{ab}$ & $20.21 \mathrm{a}$ \\
\hline ILL-4422 & $23.14 b c$ & $32.99 \mathrm{ab}$ & $35.02 \mathrm{abc}$ & $18.96 \mathrm{ab}$ & $23.51 \mathrm{ab}$ \\
\hline ILL-7664 & $18.03 \mathrm{ab}$ & $38.54 \mathrm{ab}$ & $31.45 \mathrm{ab}$ & $14.2 \mathrm{a}$ & $17.74 \mathrm{a}$ \\
\hline $\begin{array}{l}\text { ACC- } \\
21688\end{array}$ & $45.14 d$ & $43.00 \mathrm{a}$ & $49.95 c$ & $34.07 \mathrm{c}$ & $28.57 b$ \\
\hline Mean & 25.4 & 32.7 & 35.1 & 19.18 & 20.9 \\
\hline $\mathrm{CV}(\%)$ & 21.3 & 31.1 & 24.6 & 29.4 & 33.8 \\
\hline
\end{tabular}

Means within columns with different lower-case letter were non-significant $(\mathrm{P}>0.05)$.

Field Performance of Lentil Genotypes against Pea aphid

The field experiment was conducted to validate the results of lath house experiment. The mean pea aphid populations on unsprayed plots were higher at all growth stages compared to sprayed ones. The field resistance parameters used to evaluate the resistance of lentil to pea aphid were density per plant at different plant growth stage, first bloom (R-1), full bloom (R2), early pod (R3) and flat pod stage (R4), pods with grain per plant, yield per hectare.

Pea aphid population density (average number per $130 \mathrm{~cm}^{2}$ ) on protected plots

When genotypes were protected from pea aphid using dimethoate 50\% E.C at first bloom stage (R-1), they had a smaller number of pea aphid population than unprotected plots. There was pea aphid number non-significant 
difference among protected plots at all growth stage i.e. at R-1, R-2, R-3, and R-4. At first bloom stage (R-1), there was statistically significant among tested genotypes in pea aphid density (Figure 1). But, mean pea aphid number on genotypes ILL-7664, ILL-4422, ILL2595, Alemaya and R-186 at first bloom stage (R-1) was not statistically different among each other. The minimum (18.15) and maximum (25.25) number of pea aphid population at R-1 crop stage was recorded on Chalew and ACC-21688.

At full bloom stage $(\mathrm{R}-2)$, there was highly significant $(\mathrm{p}<0.01)$ among tested genotypes in pea aphid density (Figure 1). The pea aphid number on Chalew and R-186 was not significantly different, similarly no significant among ILL-2595 and ILL-7664. At early pod stage (R-3) on all tested genotypes, there was no significant, whereas at flat pod stage $(\mathrm{R}-4)$ there was highly significant $(\mathrm{p}<0.01)$ among tested genotypes (Figure 1). But there was no significant among Chalew, ILL-7664, ILL-2 595, R-186 and ACC-21688 at this growth stage. The highest and smallest pea aphid density at crop stage R-4 was 10.8 and 14.05 on ACC-21688 and R186 , respectively.

In general pea aphid population on average reached economic threshold level of $\geq 20$ per $130 \mathrm{~cm}^{2}$ at first bloom stage (R-1) but thereafter it decreased and reached density of 11.25 to 17.45 aphids per $130 \mathrm{~cm} 2$. Pea aphid population crashed perhaps due to the extended rain that at the time of flowering stage. In this season, in the second and third week of October (at R-2 and R-3 crop stage) the rain was higher than in the first week of October. It rained about $37.5 \mathrm{~mm}$ in the first week of October and $151.5 \mathrm{~mm}$ in 15 days in second and third week of October. This rain might severely affected density of pea aphid population.

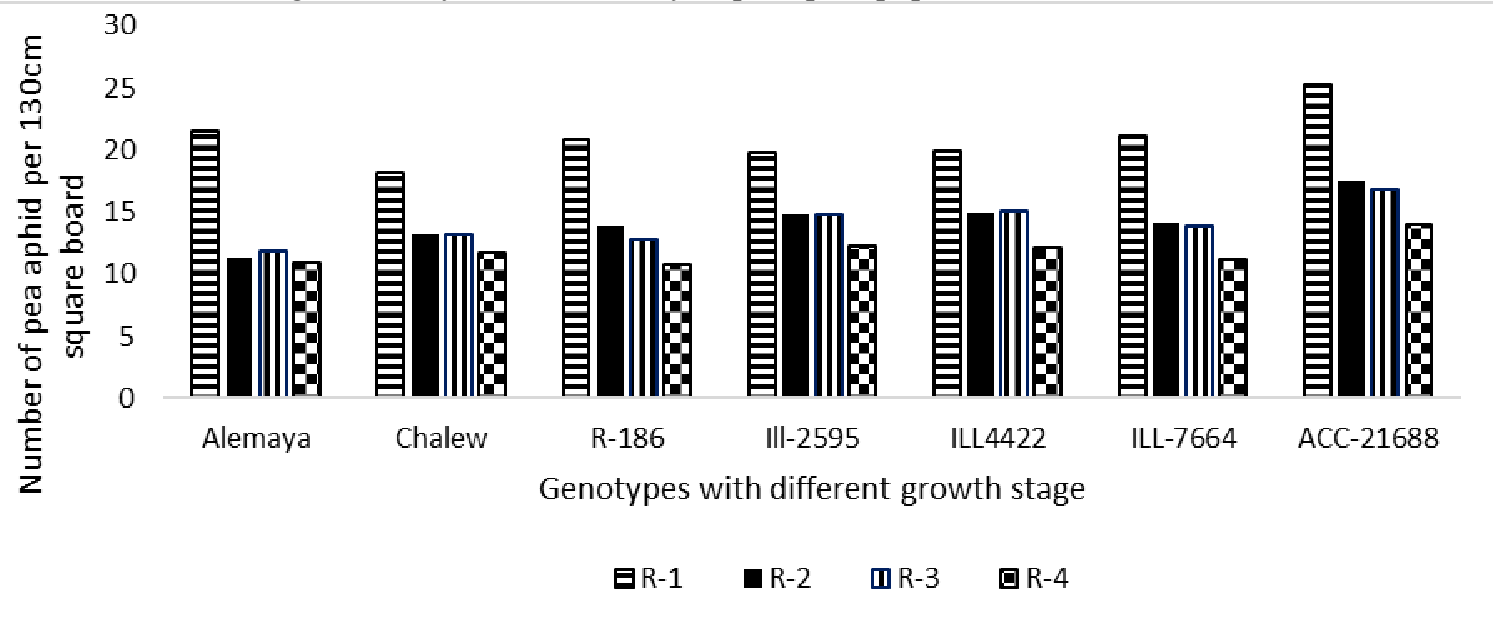

Figure 1 Pea aphid population density (average number per $130 \mathrm{~cm}^{2}$ ) in unsprayed plots, R1= first bloom stage, $\mathrm{R} 2=$ full bloom, R3= Early pod, R4= flat pod

\section{Grain yield (kg/ha) and Pod number \\ Effect of pea aphid on grain yield}

In both protected and unprotected plots there was highly significant $(\mathrm{p}<0.01)$ among tested genotypes in grain yield (Table 2). But grain yield in un protected plot on ACC-21688 and ILL-4422 showed non-significant. Significantly the highest grain yield both in unprotected and protected plots was recorded from released varieties namely, Alemaya followed by R-186 and Chalew. All tested resistant genotypes had significantly higher grain yield and lower percent reduction compared with control. Hence yield reduction is good parameter to conclude resistance level in field performance. Alemaya tolerated the pest damage and gave high yield without insecticide sprays. Based on percent yield reduction Chalew and ILL-7664 showed are good tolerance genotype next to Alemaya to pea aphid.

Grain yield percent reduction due to pea aphid was highly significantly different $(\mathrm{p}<0.01)$ among tested genotypes (Table 2). But yield percent reduction on Chalew, ILL-7664, ILL-4422 and ILL-2595 showed nonsignificant, similarly percent reduction on ACC-21688 and ILL-2595 showed non-significant. All tested genotypes had significantly lower yield percent reduction than control. Tolerant plants support large insect population with little damage or yield loss and have value in maintaining predator and parasite population (Horber, 1972). Hence genotypes which showed low yield reduction in this study (Alemaya) is more resistant based on percent of yield reduction. The lower yield reduction percentage was an indicator of the higher resistance in relative term. Tolerant plants had the ability to sustain an injury, great enough to damage a susceptible variety, without a reduction in yield. In the current field resistance study there was inconsistency in parameters to rank genotypes based on level of resistance of tested genotypes. In general plant yield loss in the current study due to pea aphid damage cause from 15 to $27.97 \%$ loss in among resistance tested genotypes and $31.23 \%$ yield loss on susceptible genotype current study due to pea aphid damage cause from 15 to $27.97 \%$ loss 
in yields among resistance tested genotypes and $31.23 \%$ yield loss on susceptible genotype. Table 2. Effect of pea aphid on yield performance of lentil genotypes ( $\mathrm{kg} / \mathrm{ha}$ ) at Chefe Donsa

\begin{tabular}{lllll}
\hline Genotypes & Protected yield & $\begin{array}{l}\text { Unprotected } \\
\text { yield }\end{array}$ & Percent reduction & $\begin{array}{l}\text { Unprotected } \\
(\%) \text { with grain }\end{array}$ \\
\hline Alemaya & $2276 \mathrm{~b}$ & $1937 \mathrm{~d}$ & $15.01 \mathrm{a}$ & $79.92 \mathrm{~b}$ \\
Chalew & $1952 \mathrm{abc}$ & $1511 \mathrm{bc}$ & $22.37 \mathrm{ab}$ & $74.16 \mathrm{ab}$ \\
R-186 & $2104 \mathrm{bc}$ & $1576 \mathrm{c}$ & $23.80 \mathrm{ab}$ & $77.69 \mathrm{ab}$ \\
ILL-2595 & $1637 \mathrm{a}$ & $1224 \mathrm{a}$ & $25.34 \mathrm{ab}$ & $76.31 \mathrm{ab}$ \\
ILL-4422 & $1782 \mathrm{a}$ & $1289 \mathrm{ab}$ & $27.97 \mathrm{~b}$ & $75.95 \mathrm{ab}$ \\
ILL-7664 & $1898 \mathrm{ab}$ & $1483 \mathrm{bc}$ & $22.11 \mathrm{ab}$ & $75.53 \mathrm{ab}$ \\
ACC-2168 & $1782 \mathrm{a}$ & $1218 \mathrm{a}$ & $31.23 \mathrm{~b}$ & $71.98 \mathrm{a}$ \\
Mean & 1917 & 1463 & 24 & 75.94 \\
CV $(\%)$ & 9.6 & 8.3 & 23.3 & 3.9 \\
\hline
\end{tabular}

Means within columns with different lower-case letter were statistically not significant different $(\mathrm{P}>0.05$, Tukey's HSD test $)$. NS $=$ statistically no-significant $(\mathrm{P}>0.05)$.

\section{Conclusion}

Lath house and field studies were conducted for better understanding of category of resistance in lentil genotypes to A. pisum. Lath house studies were conducted for better understanding of level of tolerance in lentil genotypes to A. pisum. In lath house tolerance resistance was evaluated by measuring genotypes dry plant weight reduction, plant height reduction, plant re-growth, leaf number and leaf area 12 days after infestation with 10 similar age pea aphids. Tolerance in released resistant varieties, Alemaya reduces pea aphid damage cumulatively by the reduced percent dry and fresh biomass, percent plant height reduction and increased dry biomass, plant regrowth after 12 days of infestation compared with other tested genotypes, thus Alemaya had tolerance resistance mechanism to A. pisum. Similarly, comparable tolerance was found on ILL-7664 which exhibited longer plant re-growth, increased dry biomass after 12 days of infestation compared with other tested genotypes, except Alemaya. Chalow also showed reduced percent plant height and dry biomass reduction and increased leaf number after 12 days of infestation. ILL-2595 and ILL-4422, had some level of tolerance, the remaining genotype R-186 seems to have lower level of tolerance based on most tolerance parameter.

\section{In the current open field trail}

The lower yield reduction percentage was an indicator of the higher resistance in relative term. In this regard, R186 and Alemaya, genotype showed low yield reduction in this study which is more resistant based on percent of yield reduction. In the current field resistance study there was inconsistency in parameters to rank genotypes based on level of resistance of tested genotypes.

R-186 showed poor resistance to pea aphid in lath house but it was resistance in field. This difference may due to dynamic nature of field environment. According to Adane et al. (2012), various environmental factors like location and cropping season which causes minimum and maximum temperature, rainfall, relative humidity, soil fertility, sunshine, wind direction fluctuation and management interventions like insecticidal treatment and sowing dates and the interaction of these different factors may affect crop performance positively. Study on genetic improvement of lentil differed in days to maturity (105.67, 98, 89.6 days) for R-186, Chalew, and Alemaya, respectively (Daniel et al, 2015). From this result it is clear that R-186 is a late maturing genotype comparatively and hence its field resistance might have resulted from escape of the most susceptible stage.

Using genotypes that had tolerance for pea aphid management is wise decision as it reduces selection pressure on A. pisum. Alemaya (genotype which had tolerant resistance mechanism) is more important for integrated pest management program (IPM) than all the remaining tested genotypes. According to Webster et al. (1978) there may difference between field and laboratory tests because of the dynamic nature of insect-plant interactions under field conditions, and effects of environment on growth stages.

A further advanced study should be conducted for a better understand of morphological and biochemical bases of resistance. Future research also should focus on new source of resistance.

\section{Acknowledgement}

This research Funded by EIAR

\section{REFERENCES}

Adane Tesfaye, Melaku Wale and Ferdu Azerefegne. 2012. Acyrthosiphon pisum (Harris) (Homoptera: Aphididae) feeding preference and performance on cool-season food legumes in northwestern Ethiopia. International Jcurrentnal of Pest Management, 59 (4) 319-328.

Alemtaye Andarge and Van Der Westhuizen, M.C. 2004. Mechanisms of resistance of lentil (Lens culinaris 
Medikus) genotypes to the pea aphid (Acyrthosiphon pisum Harris) (Hemiptera: Aphididae). International Jcurrentnal of Tropical Insect Science, 24 (3): 249-254.

Baker, P. B., R. H. Ratcliffe, and A. L. Steinhauer. 1981. Tolerance to hairy chinch bug (Blissus leucopterus) feeding in Kentucky bluegrass (Poa pratensis). Environmental Entomology, 10: 153-157.

Brewer, M. J., Struttmann, J.M. and Mornhinweg, D.W. 1998. Aphelinus albipodus (Hymenoptera: Aphelinidae) and Diaeretiella rapae (Hymenoptera: Braconidae) parasitism on Diuraphis noxia (Homoptera: Aphididae) infesting barley plants differing in plant resistance to aphids. Biological Control, 11: 255-61.

Daniel Admasu, Firew Mekbib and Asnake Fikre. 2015. Genetic Improvement of Lentil (Lens culinaris Medikus) Between 1980 and 2010 in Ethiopia. Malaysian Jcurrentnal of Medical and Biological Research, 2 (3): 288-289.

Dent .2000. Insect Pest Management. CAB International. Wallingford, UK.

DeLoach, C. J. 1974. Rate of increase of populations of cabbage, green peach, and turnip aphids at constant temperatures. Annals Entomological Society of America, 67: 332-340.

DZARC (Debre Zeit Agricultural Research Center).2012. Annual Report for 2000/20011, Debre Zeit, Ethiopia. $65 \mathrm{p}$.

Erskine, W., Tufail, M., Russell, A. Tyagi, MC., Rahman, MM. and Saxenal, MC. 1994. Current and future strategies in breeding lentil for resistance to biotic and abiotic stresses. Euphytica, 73: 127- 135.

Ferrari, J., H., Godfray, C. J. Faulconbridge, A. S., Prior, K. and Via, S. 2006. Population differentiation and genetic variation in host choice among pea aphids from eight host genera. Evolution, 60:1574-1584.

Hilker, M., and Fatcurrentos, N.E. 2015. Plant responses to insect egg deposition. Annual Review of Entomology, 60: 493-515.

Hodgson, C. 1991. Dispersal of apterous aphids (Homoptera, Aphididae) from their host plant and its significance. Bulletin Entomology research, 81: 417-427.

Horber, E. 1972. Plant resistance to insects. Aerie Science Review, 10: 1-11.

Karban, R. 2011. The ecology and evolution of induced resistance against herbivores. Functional Ecology, 25:339-47.

Katis, N.I., Tsitsipis, J.A., Stevens, M. and Powell. G. 2007. Transmission of Plant Viruses. pp.353-390. In: van Emden, H.F. and Harrington, R. (eds.). Aphids as Crop Pests, CAB International, Wallingford.

Kemal Ali and Tibebu Habtewold. 1994. Research on insect pests of cool-season food legumes. pp. 367-396.

Thomas, M. and Waage, J. 1996. Integration of biological control and host-plant resistance breeding. A scientific and literature review. CTA, the Netherlands

Unger, L. M. and Quisenberry, S. S. 1997. Categorization of six wheat plant introduction lines for resistance to the Russian wheat aphid (Homoptera: Aphididae). Jcurrentnal Economic Entomology, 90: 1408-1413.

Webster, J. A., Smith, D. H. and Gage, S. H. 1978. Cereal leaf beetle (Coleoptera: Chrysomelidae): influence of seeding rate of oats in populations. Great Lakes Entomology, 11:117-120.

Zhu, L. C., Smith, C.M. and Reese, J.C. 2005. Categories of resistance to greenbug (Homoptera: Aphididae) biotype $\mathrm{K}$ in wheat lines containing Aegilops tauschii genes. Jcurrentnal of Economic Entomology, 98: 2602265. 